\title{
Genetic Dissection of Stem Water-Soluble Carbohydrates and Agronomic Traits in Wheat under Different Water Regimes
}

\author{
Khan Nadia ${ }^{1,2}$, Xiaoping Chang ${ }^{1} \&$ Ruilian Jing ${ }^{1}$ \\ ${ }^{1}$ National Key Facility for Crop Gene Resources and Genetic Improvement/Institute of Crop Science, Chinese \\ Academy of Agricultural Sciences, Beijing, China \\ ${ }^{2}$ Department of Genetics, University of Karachi, Karachi, Pakistan \\ Correspondence: Ruilian Jing, National Key Facility for Crop Gene Resources and Genetic Improvement/ \\ Institute of Crop Science, Chinese Academy of Agricultural Sciences, Zhongguancun South Street No. 12, \\ Beijing 100081, China. Tel: 86-10-82105829. E-mail: jingruilian@caas.cn
}

Received: October 9, 2016

Accepted: November 20, 2016

Online Published: February 15, 2017

doi:10.5539/jas.v9n3p42

URL: http://dx.doi.org/10.5539/jas.v9n3p42

\begin{abstract}
Drought is a major environmental stress threatening wheat (Triticum aestivum L.) productivity worldwide. Although drought impedes wheat performance at all growth stages, it is more critical during the flowering and grain-filling phases and results in substantial yield losses. In this context, stem water-soluble carbohydrates (SWSC) were dissected at flowering and grain filling stages under drought stress (DS) and well-watered (WW) conditions using a population consisted of 116 wheat accessions in this research. The main goal was to dissect the genetic basis of water-soluble carbohydrates and the agronomic traits using association mapping approach and identify linked molecular markers. The results showed significant and positive correlations for stem water-soluble carbohydrates at grain filling (SWSCG) with accumulating efficiency of stem water-soluble carbohydrates (AESWSC) and grain filling efficiency at the late stage (GFEL). The accumulating and grain filling efficiency at grain filling stage could play an important role for SWSC especially under DS condition. Four favorable alleles for plant height $(\mathrm{PH})$ and grain yield (GY) were identified in two water environments. Xbarc 78-4A 163 and $X b a r c 78-4 A_{155}$ were variant alleles for $\mathrm{PH}$ which were identified in both water regimes. Whereas $X w m c 25-2 D_{151}$ and $X g w m 165-4 B_{191}$ positively linked with GY in WW. Although Xwmc420-4A 121 and $X w m c 112-2 D_{215}$ were alleles for stem water-soluble carbohydrates at flowering (SWSCF) and SWSCG in DS but the frequency were $<5 \%$ so they were considered as rare alleles. These SSR markers which explained significant level of phenotypic variability for chosen traits could be used for selection of genotypes in wheat breeding programs through marker-assisted selection.
\end{abstract}

Keywords: association mapping, drought, stem water-soluble carbohydrates, SSR markers, wheat

\section{Introduction}

Wheat is one of the three major cereals. Global annual production is 727.87 million metric tons in 2014-2015 (USDA, 2016). To ensure food for the rapidly growing world population, wheat production needs to double by 2050 (Alexandratos \& Bruinsma, 2012). Further increases in wheat production depend on higher yields rather than an increase in cropping area (Araus et al., 2003). Declining water resources challenge this notion as water availability impacts heavily on crop yields (Kang et al., 2008). Among all the abiotic stress factors that limit crop productivity, drought is the most devastating one and the most difficult to breeders' efforts. Breeding efforts in the past, to improve drought tolerance has been hindered by its quantitative genetic basis and the poor understanding of the physiological basis of yield under water-limited conditions (Tuberosa \& Salvi, 2006). Genomic approaches enable the identification and selection of chromosome regions harboring genes/QTLs (Quantitative trait loci) controlling agronomic traits and yield in crops (Collins et al., 2008; Cooper et al., 2009; Tuberosa \& Salvi, 2006). Among such approaches, association mapping is increasingly being adopted as a method complementary to traditional bi-parental linkage mapping to identify genotype-phenotype associations i.e. molecular marker-trait associations (Sorrells \& Yu, 2009; Waugh et al., 2009).

Water-soluble carbohydrates (WSC) in wheat stems are mainly composed of fructan, sucrose, glucose, and fructose, in with fructan is the major component at the late stage of WSC accumulation phase (Ruuska et al., 2006). The WSC can be accumulated in the stem and leaf sheath of cool-season cereals e.g. wheat, barley 
(Hordeum vulgare), and oats (Avena sativa) during the period from stem elongation to early phase of grain filling and serve as temporary carbohydrate reserves, commonly called the stem carbohydrate reserves (Blum, 1998; Gebbing, 2003). In general, WSC accumulate until 10 20 days after anthesis, and the reserved WSC can reach more than $40 \%$ of total stem dry weight in wheat (Rebetzke et al., 2008).

The contribution of WSC to final yield and kernel size is $10 \sim 20 \%$ of total grain weight under normal condition (Gebbing \& Schnyder, 1999). Drought stress during grain filling, often involving not only water stress but also heat, inhibits current assimilation and damages photosynthetic organs, especially leaves. When photosynthetic activity is suppressed, the reserved WSC play a more important role in partial compensation of the reduced carbon supply. In addition, drought induced reserved WSC mobilization with higher efficiency, potentially contributing up to $70 \%$ of grain dry matter (Goggin \& Setter, 2004; Rebetzke et al., 2008). Therefore WSC is a major contributor to wheat grain yield and grain size in all environments but especially where photosynthesis is compromised as occurs where water is limiting (McIntyre et al., 2012). Grain yield depends on carbon from two resources: flag leaf photosynthesis and remobilization of water-soluble carbohydrates, mainly fructans, from the wheat stems (Yang \& Zhang, 2006). In term, high water-soluble carbohydrate content in the stem has been suggested as a selection criterion for use inbreeding. WSC QTL have been reported in rice (Nagata et al., 2002; Takai et al., 2005), wheat (Rebetzke et al., 2008; Yang et al., 2007), maize (Thévenot et al., 2005), barley (Teulat et al., 2001) and perennial rye grass (Turner et al., 2006). With the rapid increases in number of molecular markers, association analysis has become an important tool for dissection of complex traits (Bradbury et al., 2007).

The main objective of this research is to find out the favorable alleles responsible for expression of water-soluble carbohydrates and important agronomical traits by association mapping to help breeders to improve their breeding programs through marker-assisted selection.

\section{Methods}

\subsection{Plant Materials and Field Trials}

The plant material was a population consisted of 116 winter wheat genotypes, which were collected from the different regions of China, including landraces, advanced lines and modern cultivars released from 1940s to 2000s. The wheat accessions were planted in the experiment station of the Institute of Crop Science, Chinese Academy of Agricultural Sciences at Changping $\left(116^{\circ} 13^{\prime} \mathrm{E} ; 40^{\circ} 13^{\prime} \mathrm{N}\right)$, Beijing in September $25^{\text {th }} 2013$ and harvested in the mid of June 2014.

The experimental unit was a plot consisted of four rows of $2 \mathrm{~m}$ length with row spaced $30 \mathrm{~cm}$ apart. Forty seeds were sown in each row. The field plots were subjected to two water treatments: full irrigation (well-watered, WW) and rain fed (drought stress, DS) recorded $163 \mathrm{~mm}$ of rainfall during 2013 2014 growing season. The WW plots were watered with $750 \mathrm{~m}^{3} / \mathrm{ha}(75 \mathrm{~mm})$ at the pre-overwintering, booting and flowering stages. The amount of rainfall was insufficient during each corresponding period. A randomized complete block design with three replicates was used for both WW and DS treatments. Plants were scored for the following agronomic, physiological and developmental traits: days to heading (DTH), days to flowering (DTF), flag leaf area (FLA), chlorophyll content at flowering (CCF), chlorophyll content at grain filling (CCG), plant height (PH), peduncle length (PL), spike length (SL), length of second internode from the top (LSIT), length of internodes below second internode from the top (LIBSIT), number of spikes per plant (SP), number of spikelets per spike (NSPS), sterile spikelet at the top (SST), sterile spikelet at the middle (SSM), sterile spikelet at the base (SSB), number of grains per spike (NGS), grain yield per plant (GY), grain yield per plot (GYP) and thousand-grain weight (TGW).

\subsection{Phenotyping of Stem WSC and TGW}

The five main stems were cut from the soil surface at two morphological stages, viz. flowering and mid-grain filling (14 days after flowering). Samples were taken from the mid-part of second row of each plot. Leaf blades were removed and the stems with leaf sheaths were cut into two parts i.e. the stem and the spike. The fresh samples were killed at $105^{\circ} \mathrm{C}$ for 30 minutes and then keep at $80^{\circ} \mathrm{C}$ to dehydrate until a constant dry weight. Stem samples of each accession were chipped into $2 \sim 5 \mathrm{~mm}$ length. The stem WSC was determined by the near-infrared reflectance spectroscopy (NIRS) regression models (Wang et al., 2011). Briefly, at the first step, partial least square regression models for predicting WSC in the target parts of wheat were developed using selected wavelength regions, spectroscopic pretreatments and the latent variables included in each model. The total amounts of WSC (mg/g dry weight) in each sample were also measured by chemical assay (anthrone colorimetric assay), and used for the cross validation. The NIRS regression models were highly accurate in determination of the true values of WSC measured by chemical assay in the wheat organs tested, according to 
high coefficients of determination of the true values of WSC measured by chemical assay in the wheat organs tested, according to high coefficients of determination $\left(R^{2}>0.992\right)$ and low root mean square errors of prediction $($ RMSEP $<0.228)$.

We obtained stem WSC at the flowering (SWSCF) and mid-grain filling (SWSCG) stages. Accumulating efficiency of SWSC (AESWSC) was estimated by [(SWSCG-SWSCF)/SWSCG] $\times 100 \%$. Spikes corresponding to main stem samples were collected at the mid-grain filling for each accession to obtain thousand-grain weight (TGWG). In addition, the grain filling efficiencies at the early period (before 14 days after flowering) (GFEE) and the grain filling efficiencies at the late period (from 14 DAF to grain maturity) (GFEL) were assessed by $(\mathrm{TGWG} / \mathrm{TGWM}) \times 100 \%$ and $[(\mathrm{TGWM}-\mathrm{TGWG}) / \mathrm{TGWM}] \times 100 \%$, respectively. TGWM: thousand-grain weight at maturity stage.

\subsection{Genotyping by SSR Markers}

Seedling leaves were used as the experimental material. Leaf samples were collected from one hundred and sixteen genotypes. Experiment set in vitro and twenty seeds placed in each petri plate. First leaves were collected for DNA extraction. DNA extracted by DNA Quick Plant System Kit (Tiangen Bio. Co. LTD, Beijing, China). Selection of 92 SSR markers based on evenly distributed on different chromosomes and/or linked with WSC or investigated agronomic traits. These SSR markers were found on chromosome 1A, 1D, 2A, 3B, 4A, 4B, 5A, 6B, $7 \mathrm{~A}, 7 \mathrm{~B}$ and 7D, respectively. SSR analysis was conducted using 92 primer pairs directed to the amplification of di- and tri nucleotide microsatellite loci, originally developed in bread wheat within five different research programs, WMS Wheat Microsatellite (Röder et al., 1998), WMC Wheat Microsatellite Consortium (Gupta et al., 2002), BARC USDA-ARS Beltsville Agricultural Research Center (Song et al., 2005), CFA and CFD (Guyomarc'h et al., 2002; Sourdille et al., 2001). Among 92 primers, sixty primer pairs for wheat microsatellite loci were synthesized by Sangon Biotech (Shanghai) Company. For each primer pair, the sequence of original forward primer was redesigned by adding a universal M13-tail (5'CACGACGTTGTAAAACGAC-3') to their 5' ends. Thirty-two primers were used as fluorescent markers. The universal M13 primers were labelled with different fluorescence dyes i.e. blue and green.

The PCR was conducted in a total volume of $15 \mu$, containing 20 ng genomic DNA, 10 X supplied PCR buffer including $1.2 \mathrm{mM}$ of $\mathrm{MgCl}_{2}, 2 \mathrm{mM}$ of dNTPs, 5 unit/ $\mu$ of Taq DNA polymerase, $2 \mu \mathrm{M}$ of primer. Amplification reactions were conducted using a Senso Quest lab cycler. Gradient PCR was used to determine optimal annealing temperature for each primer pair. The M13 primers were labelled with different fluorescent dyes i.e. blue and green, allowing done PCR again with the following reaction mixture containing $162 \mu 1$ M13 dye (AB Applied Biosystem, USA), PCR buffer $9 \mu \mathrm{l}$, Taq DNA polymerase $7.2 \mu$ l. Added $2.1 \mu \mathrm{l}$ of above mixture in 96 well plate that already amplified at above mentioned conditions. This mixture was further amplified under the following conditions $94{ }^{\circ} \mathrm{C}$ for $5 \mathrm{~min} ; 16$ cycles of $94{ }^{\circ} \mathrm{C}$ for $45 \mathrm{~s}, 56^{\circ} \mathrm{C}$ for $45 \mathrm{~s}$ and $72{ }^{\circ} \mathrm{C}$ for $45 \mathrm{~s}$; followed by a 10 min extension at $72{ }^{\circ} \mathrm{C}$. The PCR products were analyzed by electrophoresis in $2 \%$ agarose gel. The PCR were carried out separately for each microsatellite and the mixture of PCR products of three different markers with different dyes was made for simultaneous detection of the amplified alleles. Sequencing of 92 simple-sequence-repeat (SSR) loci has done by ABI3730 DNA analyzer. The PCR products were analyzed by Gene Mapper Software. The polymorphism information content (PIC) values (Botstein et al., 1980) were calculated using Power Marker software v3.25 (Liu \& Muse, 2005). Population structure was estimated by STRUCTURE v2.3.2 using data from 92 SSR markers. Twenty subpopulations $(k=1$ to 20$)$ were set with a burn-in period of 50,000 iterations and a run of 500,000 replications of Markov Chain Monte Carlo after burn in. The $\Delta k$ method was applied according to LnP(D) in STRUCTURE, and the output and result were estimated (Pritchard et al., 2000).

\subsection{Marker-Trait Association and Statistical Analysis}

Association between markers and traits was calculated using a general linear model (GLM) method in TASSEL v2.1 (Yu et al., 2006). The population structure matrix (Q) obtained from the STRUCTURE software and relative kinship matrix ( $k$ matrix) derived from the unlinked marker data estimated by TASSEL v2.1 were combined to covariate in the association tests to reduce false positive rate. The significant marker-trait associations were declared by $P \leq 0.01$ and the magnitude of the allele effects were evaluated by $R^{2}$-marker. Analysis of variance (ANOVA) was conducted using SPSS 16.0. Pearson's correlation coefficient among the traits under two water regimes were calculated by SPSS 16.0. Broad sense heritability $\left(h^{2}{ }_{B}\right)$ was computed by QTL IciMapping (http://www.isbreeding.net/). 


\section{Results}

\subsection{Drought Stress Induces SWSC}

On the basis of the ANOVA, the SWSC of 116 genotypes at flowering and grain filling stages were highly affected by the DS. The mean square value of SWSCG under drought stress condition was significantly higher than that under well-watered condition, but the traits such as AESWSC, GFEE, GFEL, and TGWG showed non-significant differences (Table 1).

Table 1. Mean squares for various traits under two water regimes

\begin{tabular}{|c|c|c|}
\hline Traits & MS & $\mathrm{CV}(\%)$ \\
\hline SP & $14.26^{* * *} / 12.72^{* * * *}$ & $0.26 / \mathbf{0 . 2 3}$ \\
\hline SL & $2.94^{* * *} / 3.92^{* * * *}$ & $0.13 / \mathbf{0 . 1 4}$ \\
\hline PL & $56.37^{* * *} / 89.08^{* * * *}$ & $0.22 / \mathbf{0 . 2 0}$ \\
\hline LSIT & $21.73^{* * *} / \mathbf{4 2 . 2 3} 3^{* * * *}$ & $0.19 / \mathbf{0 . 1 8}$ \\
\hline LIBSIT & $251.32^{* * * /} \mathbf{4 8 7} .62^{* * * *}$ & $0.31 / \mathbf{0 . 3 2}$ \\
\hline NSPS & $4.97^{* * *} / 4.85^{* * *}$ & $0.08 / \mathbf{0 . 0 8}$ \\
\hline SST & $0.65^{* * *} / \mathbf{0 . 2 8} 8^{* * *}$ & $1.21 / \mathbf{1 . 1 9}$ \\
\hline SSM & $0.007^{*} / \mathbf{N D}$ & 3.97/ND \\
\hline SSB & $1.41^{* * *} / \mathbf{0 . 6 5} \mathbf{5}^{* * *}$ & $0.34 / \mathbf{0 . 5 6}$ \\
\hline NGS & $80.21^{* * *} / \mathbf{3 6 . 1 2} 2^{* * *}$ & $0.17 / \mathbf{0 . 1 3}$ \\
\hline GYP & $100726.78^{* * *} / \mathbf{1 9 9 6 5 0 . 5 5 ^ { * * * * }}$ & $0.38 / \mathbf{0 . 4 0}$ \\
\hline TGW & $84.34^{* * *} / 65.97^{* * *}$ & $0.18 / \mathbf{0 . 1 5}$ \\
\hline $\mathrm{PH}$ & $658.11^{* * *} / 1176.94^{* * * *}$ & $0.21 / \mathbf{0 . 2 0}$ \\
\hline DTH & $12.49^{* * *} / \mathbf{1 5 . 9 8}^{* * *}$ & $0.01 / \mathbf{0 . 0 2}$ \\
\hline DTF & $9.61^{* * *} / \mathbf{1 5 . 2 6} 6^{* * *}$ & $0.01 / \mathbf{0 . 0 1}$ \\
\hline FLA & $5.73^{* * *} / \mathbf{1 2 . 4 3} 3^{* * *}$ & $0.21 / \mathbf{0 . 2 2}$ \\
\hline GY & $978.30^{* * *} / \mathbf{1 8 6 7 . 4 6}^{* * * *}$ & $0.26 / \mathbf{0 . 2 7}$ \\
\hline $\mathrm{CCF}$ & $38.42^{* * *} / \mathbf{3 2 . 9 4} 4^{* * *}$ & $0.08 / \mathbf{0 . 0 7}$ \\
\hline CCG & $85.52^{* * *} / \mathbf{9 2 . 5 7 2} 2^{\mathrm{NS}}$ & $0.15 / \mathbf{0 . 2 3}$ \\
\hline SWSCF & $2351.22^{* * *} / \mathbf{2 5 6 3 . 5 5 ^ { * * * }}$ & $0.17 / \mathbf{0 . 2 3}$ \\
\hline SWSCG & $3972.17^{* * *} / 3643.75^{* * *}$ & $0.17 / \mathbf{0 . 2 2}$ \\
\hline AESWSC & $1124.08^{\mathrm{NS}} / \mathbf{1 1 2 6 . 1 9 ^ { \mathrm { NS } }}$ & $0.55 / \mathbf{0 . 6 3}$ \\
\hline GFEE & $1141.58^{\mathrm{NS}} / \mathbf{1 1 1 5 . 1 9} \mathbf{9 S}^{\mathrm{NS}}$ & $0.27 / \mathbf{0 . 3 3}$ \\
\hline GFEL & $1117.45^{\mathrm{NS}} / \mathbf{1 1 3 5 . 6 2} \mathbf{2}^{\mathrm{NS}}$ & $0.24 / \mathbf{0 . 2 7}$ \\
\hline TGWG & $1108.06^{\mathrm{NS}} / \mathbf{1 1 5 5 . 1 1}^{\mathrm{NS}}$ & $0.29 / \mathbf{0 . 3 1}$ \\
\hline
\end{tabular}

Note. MS: mean squares; ${ }^{* *}$ and ${ }^{* * *}$ indicate $P=0.01 P=0.001$, respectively; CV: coefficient of variation; NS: non-significant; ND: not determined; un bold value shows under DS while bold value shows under WW conditions; DS: drought stress; WW: well-watered; SP: number of spikes per plant; SL: spike length; PL: peduncle length; LSIT: length of second internode from the top; LIBSIT: length of internodes below second internode from the top; NSPS: number of spikelet per spike; SST: sterile spikelet at the top; SSM: sterile spikelet at the middle; SSB: sterile spikelet at the base; NGS: number of grains per spike; GYP: grain yield per plot; TGW: thousand-grain weight; PH: plant height; DTH: days to heading; DTF: days to flowering; FLA: flag leaf area; GY: grain yield per plant; CCF: chlorophyll content at flowering; CCG: chlorophyll content at grain filling; SWSCF: stem water-soluble carbohydrates at flowering stage; SWSCG: stem water-soluble carbohydrates at grain filling stage; AESWSC: accumulation efficiency of stem water-soluble carbohydrates; GFEE: grain filling efficiency at the early stage; GFEL: grain filling efficiency at the late stage; TGWG: thousand-grain weight at grain filling stage.

SWSC at flowering stage ranged from 140.75 to $298.5 \mathrm{mg} / \mathrm{g}$ whereas SWSC at grain filling stage ranged from 140.63 to $346.37 \mathrm{mg} / \mathrm{g}$ under drought stress (Figure 1). It is reported that stem water-soluble carbohydrates are a major carbon source for grain filling under drought stress (Zhang et al., 2016). In addition, stem water-soluble carbohydrates buffer wheat grain yield against drought stress for photosynthesis during the grain filling stage (Li 
et al., 2015). In the present study, moderate to high broad sense heritability for SWSC at both stages under WW and DS conditions were estimated ranged from $0.76 \sim 0.78$ to $0.71 \sim 0.80$ (Appendix 1).
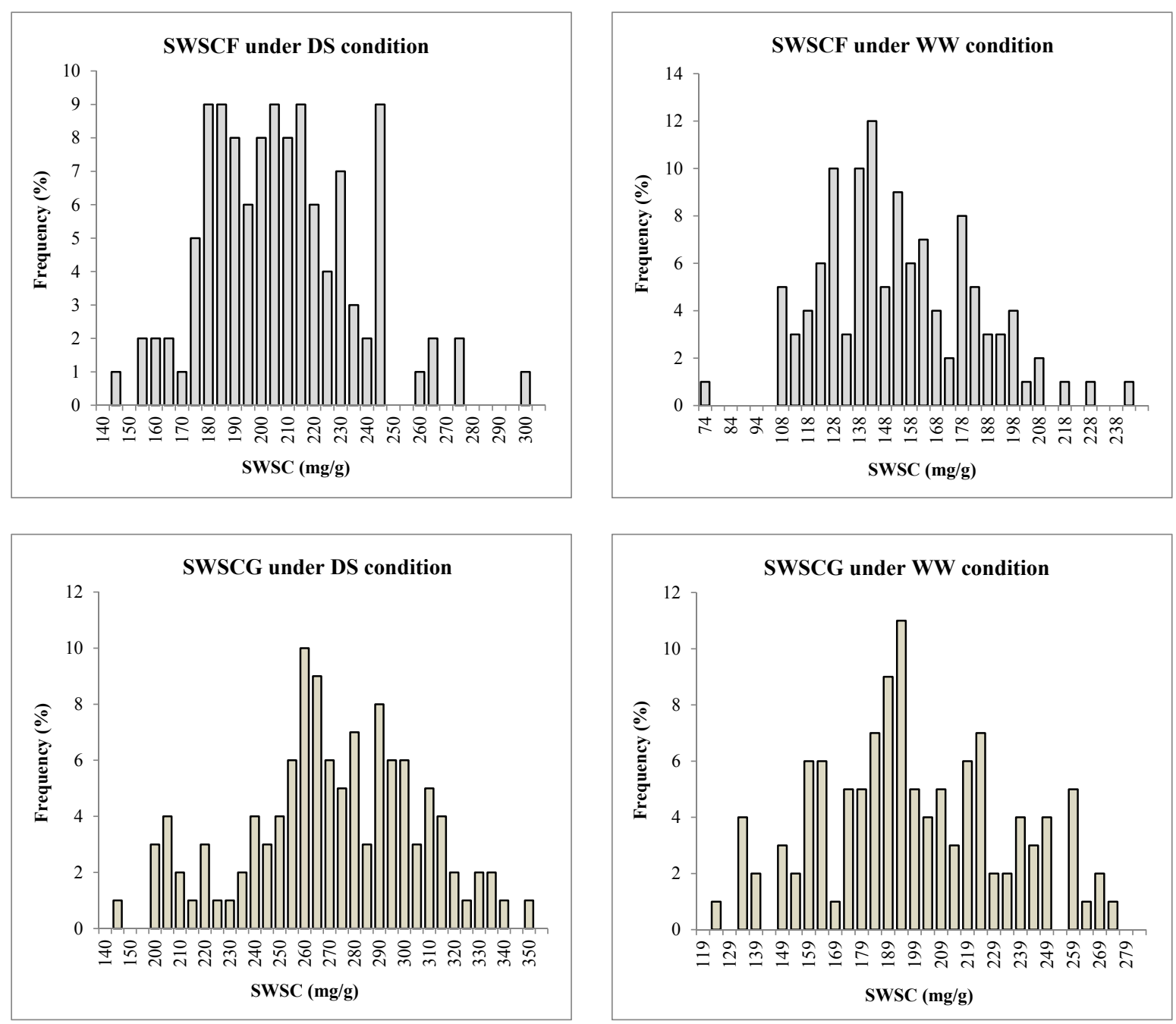

Figure 1. Frequency distribution of SWSC at flowering and grain filling stages under DS and WW condition Note. DS: drought stress; WW: well-watered; SWSC: stem water-soluble carbohydrates; SWSCF: stem water-soluble carbohydrates at flowering stage; SWSCG: stem water-soluble carbohydrates at grain filling stage.

\subsection{SWSC Correlated with Other Traits}

Correlation coefficients among all traits under the two water regimes are given in Table 2. The traits associated with SWSC at two different growth stages such as SWSCF and SWSCG were highly significant correlation with each other under WW and DS conditions. SWSCF showed a highly significantly negative correlation with AESWSC under both water conditions. While, SWSCF had a significantly positive relationship with thousand-grain weight at grain filling (TGWG) and maturity (TGWM) under DS condition. In WW condition, SWSCF were also significantly positive correlation with TGWG and TGWM but had smaller values of correlation. However, SWSCG exhibited a highly positive correlation with AESWSC, TGWM and grain filling efficiency at late stage (GFEL) in both environments. 
Table 2. Pearson's correlation coefficients for traits under two water regimes

\begin{tabular}{llllllll}
\hline Traits & SWSCF & SWSCG & AESWSC & TGWG & TGWM & GFEE & GFEL \\
\hline SWSCF & & $0.402^{* *}$ & $-0.472^{* *}$ & $0.294^{* *}$ & $0.300^{* *}$ & 0.085 & 0.084 \\
SWSCG & $0.486^{* *}$ & & $0.540^{* *}$ & $0.153^{* *}$ & $0.460^{* *}$ & $-0.155^{* *}$ & $0.337^{* *}$ \\
AESWSC & $-0.462^{* *}$ & $0.511^{* *}$ & & $-0.147^{* *}$ & $0.130^{*}$ & $-0.227^{* *}$ & $0.229^{* *}$ \\
TGWG & $0.130^{*}$ & 0.099 & -0.042 & & $0.341^{* *}$ & $0.758^{* *}$ & $-0.385^{* *}$ \\
TGWM & $0.293^{* *}$ & $0.576^{* *}$ & $0.298^{* *}$ & $0.159^{* *}$ & & $-0.328^{* *}$ & $0.727^{* *}$ \\
GFEE & -0.026 & $-0.182^{* *}$ & $-0.182^{* *}$ & $0.870^{* *}$ & $-0.325^{* *}$ & & $-0.887^{* *}$ \\
GFEL & $0.145^{* *}$ & $0.386^{* *}$ & $0.268^{* *}$ & $-0.610^{* *}$ & $0.677^{* *}$ & $-0.916^{* *}$ &
\end{tabular}

Note. Values in the upper right portion are for DS; those at the lower left are for WW. ${ }^{*}:$ indicates $P=0.05$, and ${ }^{* *}$ : $P=0.01$.

There was a positive and significant correlation between SWSCG and TGWG under DS while non-significant correlation was noted for the same trait under WW condition. Whereas SWSCG had a significant and negative association with grain filling efficiency at early stage (GFEE) under two water conditions. AESWSC was significantly correlated with GFEE and GFEL under both conditions. TGWG had a highly significant correlation with GFEE $\left(r^{2}=0.758^{* *}\right.$ and $\left.0.870^{* *}\right)$ in both environments DS and WW. Whereas TGWG and GFEL was negative correlation, the effects were opposite for TGWM with GFEE and GFEL under two water conditions (Table 2).

\subsection{SSR Marker Polymorphism and Population Structure}

Ninety two SSR markers were scored across 116 wheat accessions to proceed to the population structure assessment and association analysis. A total of 1600 alleles were amplified among the 116 wheat accessions, and the number of alleles per locus ranged from 3 49 with an average of 17.39. Frequencies of the 92 SSR loci ranged from 0.08 (Xwmc757) to 0.95 (Xgwm515). Besides, the average PIC value was 0.71 with a range of 0.09 0.96. The analysis of population structure was inferred with the STRUCTURE 2.3.2 software (Figure 2A). According to the method of Evanno et al. (2005), $\Delta k$ was plotted against the number of subpopulations $k$ (Figure 2B). The maximum value of $\Delta k$ occurred at $k=5$, such that $k=5$ (five subpopulations) was defined to provide the optimal structure (Figure 3 ).

(A)

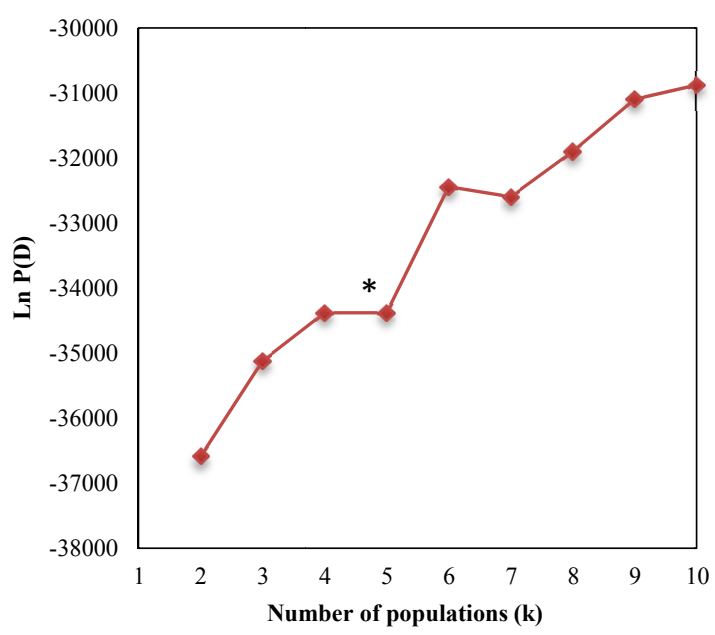

(B)

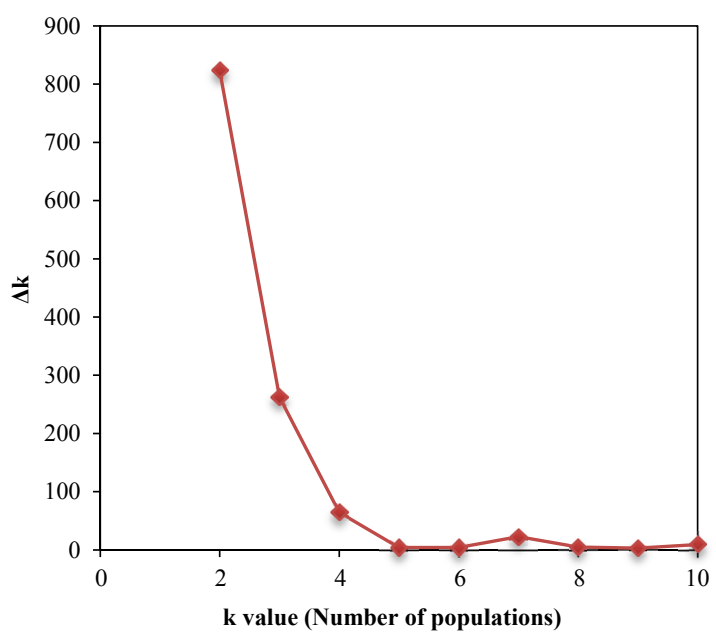

Figure 2. Population structure analysis of 116 wheat accessions based on 92 SSR markers

Note. (A) Estimated Ln P(D) by STRUCTURE; (B) Estimated $\Delta k$ of STRUCTURE analysis. 


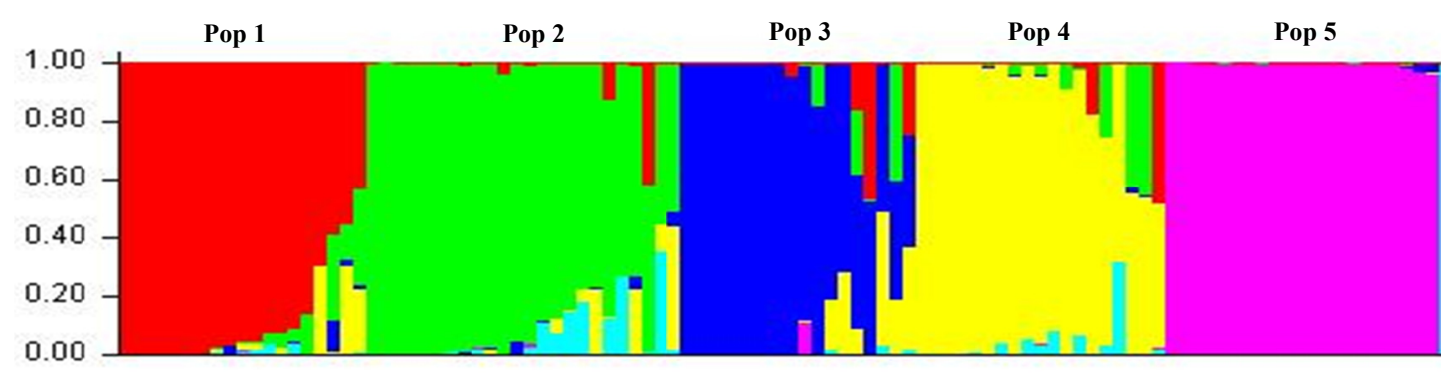

Figure 3. Population structure analysis of 116 wheat accessions based on 92 SSR markers. Five subpopulations inferred by structure analysis. Each of the 116 genotypes is represented by a different colors indicate different subpopulation

\subsection{Marker-Trait Associations}

Marker-trait association was tested through the general linear model. Based on the critical $P$-value less than 0.01 with 92 SSR markers for traits, identified 31 marker-trait associations (MTAs) involving 17 SSR markers distributed on the nine chromosomes for 13 traits and the $R^{2}$ ranges from 0.15 to 0.44 . Among the MTAs, 12 SSR markers were specific for single traits, and the rest consisted of associations of up to five traits (Table 3). LIBSIT under DS was involved in the highest number of (5), distributing on the different chromosomes (2D, 3B, 4A and $5 \mathrm{~A}$ respectively), and MTAs (4) were found for LIBSIT under WW condition on the chromosomes (2A, 2D, 3B and 4A respectively), followed by TGWG (4) in DS. The fewest MTAs were associated with LSIT (1) in both conditions. Each trait was associated with at least one (CCG, DTH, GY, GYP, LSIT, PL, SP, SWSCF and SWSCG) and the maximum five (LIBSIT) chromosomes.

The highest number of associated markers were found on chromosome 2D, 4A and $5 \mathrm{~A}$ ( 3 each), followed by $3 \mathrm{~B}$ and 4B (2 each), with the least on 1A, 1D, 2A and 7D (1 each). Under drought stress condition, LIBSIT was significantly associated with 5 markers with $R^{2}$ ranged from 0.18 to 0.27 . The 5 MTAs were spread over chromosomes 2D $(18 \mathrm{cM}), 3 \mathrm{~B}(61 \mathrm{cM}), 4 \mathrm{~A}(7 \mathrm{cM}, 71 \mathrm{cM}), 5 \mathrm{~A}(52 \mathrm{cM})$. Under well-watered condition, LIBSIT was significantly associated with 4 markers with $R^{2}$ ranged from 0.21 to 0.26 . The 4 MTAs were found on chromosomes 2A, 2D, 3B and 4A. TGWG was significantly associated with 4 markers with $R^{2}$ ranged from 0.27 to 0.42 under DS. The 4 MTAs were observed on chromosomes $1 \mathrm{D}, 3 \mathrm{~B}, 5 \mathrm{~A}$ and $7 \mathrm{D}$. PH was significantly associated with 3 markers with $R^{2}$ ranged from 0.18 to 0.23 under DS. The 3 MTAs were identified on chromosomes 2D $(18 \mathrm{cM}), 4 \mathrm{~A}(7 \mathrm{cM}, 71 \mathrm{cM})$. However under WW condition $\mathrm{PH}$ was significantly associated with only one marker with $R^{2} 0.21$. This MTA was on 4A $(71 \mathrm{cM})$. TGW was significantly associated with 2 markers with $R^{2}$ ranged from 0.26 to 0.30 under DS, and from 0.28 to 0.31 under WW condition. The 2 MTAs for TGW in DS were located on 4B $(31 \mathrm{cM}), 5 \mathrm{~A}(61 \mathrm{cM})$, and under WW on 4A $(18 \mathrm{cM})$ and $4 \mathrm{~B}(31 \mathrm{cM})$ chromosomes. Only one marker was identified associated with the other individual trait.

$X w m c 25-2 D$ was associated with LIBSIT under both conditions, whereas it was also associated with GY under WW and PH under DS. Xbarc78-4A was significantly associated with PH and LIBSIT under both conditions. $X w m c 420-4 A$ was significantly associated with LIBSIT, PH, PL, and SWSCF under only DS while LSIT under both conditions. Xgwm 149-4A was significantly associated with TGW under both conditions whereas it was also associated with SP under DS. Xgwm285-3B was significantly associated with LIBSIT in both DS and WW conditions. 
Table 3. Favorable alleles associated with phenotypic traits

\begin{tabular}{|c|c|c|c|c|c|c|c|c|c|}
\hline Water regimes & Traits & Chr. & Locus & $\begin{array}{l}\text { Chr. Position } \\
\text { (cM) }\end{array}$ & $\begin{array}{l}\text { Favorable allele } \\
\text { (bp) }\end{array}$ & $\begin{array}{l}\text { Frequency } \\
(\%)\end{array}$ & Mean $\pm \mathrm{SE}$ & $P$-value & Effect \\
\hline \multirow[t]{40}{*}{ DS } & DTH & $1 \mathrm{~A}$ & Xbarc148 & 57 & 163 & 0.86 & $205 \pm 0$ & 0.0001 & Negative \\
\hline & & & & & Others & 99.14 & $209 \pm 0.1$ & & \\
\hline & TGWG & $1 \mathrm{D}$ & Xwmc432 & 23 & 197 & 0.86 & $20.5 \pm 0$ & 0.0007 & Positive \\
\hline & & & & & others & 99.14 & $9.9 \pm 0.1$ & & \\
\hline & LIBSIT & $2 \mathrm{D}$ & Xwmc25 & 18 & 181 & 0.86 & $52.0 \pm 0$ & 0.0006 & Positive \\
\hline & & & & & others & 99.14 & $28 \pm 0.8$ & & \\
\hline & PH & $2 \mathrm{D}$ & Xwmc25 & 18 & 181 & 0.86 & $109 \pm 0$ & 0.0003 & Positive \\
\hline & & & & & others & 99.14 & $75 \pm 1.3$ & & \\
\hline & SWSCG & $2 \mathrm{D}$ & Xwmc112 & 28 & 215 & 0.86 & $346.3 \pm 0$ & 0.0009 & Positive \\
\hline & & & & & others & 99.14 & $267.7 \pm 3.3$ & & \\
\hline & LIBSIT & $3 \mathrm{~B}$ & Xgwm285 & 61 & 245 & 0.86 & $45.7 \pm 0$ & 0.0005 & Positive \\
\hline & & & & & others & 99.14 & $30.0 \pm 0.8$ & & \\
\hline & TGWG & $3 \mathrm{~B}$ & Xbarc164 & 70 & 214 & 0.86 & $20.5 \pm 0$ & 0.0003 & Positive \\
\hline & & & & & others & 99.14 & $9.9 \pm 0.1$ & & \\
\hline & LIBSIT & $4 \mathrm{~A}$ & Xbarc78 & 71 & 163 & 5.17 & $45.9 \pm 1.2$ & 0.0000 & Positive \\
\hline & & & & & others & 94.83 & $29.8 \pm 0.8$ & & \\
\hline & $\mathrm{PH}$ & $4 \mathrm{~A}$ & Xbarc78 & 71 & 163 & 5.17 & $100 \pm 2.9$ & 0.0002 & Positive \\
\hline & & & & & others & 94.83 & $75 \pm 1.3$ & & \\
\hline & LIBSIT & $4 \mathrm{~A}$ & Xwmc420 & 7 & 123 & 0.86 & $52.0 \pm 0$ & 0.0000 & Positive \\
\hline & & & & & others & 99.14 & $30.8 \pm 0.8$ & & \\
\hline & LSIT & $4 \mathrm{~A}$ & Xwmc420 & 7 & 121 & 1.72 & $19.5 \pm 0$ & 0.0001 & Positive \\
\hline & & & & & others & 98.28 & $16.3 \pm 0.2$ & & \\
\hline & $\mathrm{PH}$ & $4 \mathrm{~A}$ & Xwmc420 & 7 & 123 & 0.86 & $109 \pm 0$ & 0.0000 & Positive \\
\hline & & & & & others & 99.14 & $76 \pm 1.3$ & & \\
\hline & PL & $4 \mathrm{~A}$ & Xwmc420 & 7 & 121 & 1.72 & $27.4 \pm 0$ & 0.0005 & Positive \\
\hline & & & & & others & 98.27 & $21.4 \pm 0.4$ & & \\
\hline & SWSCF & $4 \mathrm{~A}$ & Xwmc420 & 7 & 121 & 1.72 & $191.9 \pm 6.8$ & 0.0009 & Negative \\
\hline & & & & & others & 98.28 & $202.1 \pm 2.6$ & & \\
\hline & TGW & $4 \mathrm{~B}$ & Xgwm149 & 31 & 139 & 0.86 & $37.9 \pm 0$ & 0.0002 & Positive \\
\hline & & & & & others & 99.14 & $32.1 \pm 0.4$ & & \\
\hline & SP & $4 \mathrm{~B}$ & Xgwm149 & 31 & 137 & 0.86 & $16 \pm 0$ & 0.0000 & Positive \\
\hline & & & & & others & 99.14 & $10 \pm 0.2$ & & \\
\hline & LIBSIT & $5 \mathrm{~A}$ & Xgwm293 & 52 & 204 & 0.86 & $44 \pm 0$ & 0.0004 & Positive \\
\hline & & & & & others & 99.14 & $30.1 \pm 0.8$ & & \\
\hline & TGWG & $5 \mathrm{~A}$ & Xgwm415 & 56 & 136 & 0.86 & $6.6 \pm 0$ & 0.0000 & Negative \\
\hline & & & & & others & 99.14 & $9.9 \pm 0.2$ & & \\
\hline & TGW & $5 \mathrm{~A}$ & Xgwm 304 & 61 & 216 & 0.86 & $19.0 \pm 0$ & 0.0007 & Negative \\
\hline & & & & & others & 99.14 & $32.3 \pm 0.48$ & & \\
\hline & TGWG & $7 \mathrm{D}$ & Xgwm295 & 77 & 229 & 0.86 & $16.7 \pm 0$ & 0.0005 & Positive \\
\hline & & & & & others & 99.14 & $9.9 \pm 0.18$ & & \\
\hline \multirow[t]{11}{*}{ WW } & LIBSIT & $2 \mathrm{~A}$ & Xwmc296 & 49 & 150 & 0.86 & $61.8 \pm 0$ & 0.0009 & Positive \\
\hline & & & & & others & 99.14 & $40.9 \pm 1.1$ & & \\
\hline & CCG & $2 \mathrm{D}$ & Xgwm 382 & 100 & 114 & 1.72 & $45.1 \pm 0$ & 0.0010 & Positive \\
\hline & & & & & others & 98.28 & $39.8 \pm 0.6$ & & \\
\hline & LIBSIT & $2 \mathrm{D}$ & $X w m c 25$ & 18 & 181 & 0.86 & $64.3 \pm 0$ & 0.0006 & Positive \\
\hline & & & & & others & 99.14 & $40.73 \pm 1.1$ & & \\
\hline & GY & $2 \mathrm{D}$ & $X w m c 25$ & 18 & 151 & 29.31 & $143.39 \pm 3.6$ & 0.0001 & Positive \\
\hline & & & & & others & 70.69 & $133.1 \pm 2.8$ & & \\
\hline & LIBSIT & $3 \mathrm{~B}$ & Xgwm285 & 61 & 251 & 1.72 & $59.5 \pm 0$ & 0.0008 & Positive \\
\hline & & & & & others & 98.28 & $40.4 \pm 1.1$ & & \\
\hline & LIBSIT & $4 \mathrm{~A}$ & Xbarc78 & 71 & 140 & 0.86 & $53.8 \pm 0$ & 0.0000 & Positive \\
\hline
\end{tabular}




\begin{tabular}{|c|c|c|c|c|c|c|c|c|}
\hline & & & & others & 99.14 & $41.7 \pm 1.1$ & & \\
\hline \multirow[t]{2}{*}{$\mathrm{PH}$} & \multirow[t]{2}{*}{$4 \mathrm{~A}$} & \multirow[t]{2}{*}{ Xbarc 78} & \multirow[t]{2}{*}{71} & 155 & 15.51 & $84 \pm 3.5$ & \multirow[t]{2}{*}{0.0000} & \multirow[t]{2}{*}{ Negative } \\
\hline & & & & others & 84.49 & $105 \pm 1.9$ & & \\
\hline \multirow[t]{2}{*}{ LSIT } & \multirow[t]{2}{*}{$4 \mathrm{~A}$} & \multirow[t]{2}{*}{ Xwmc420 } & \multirow[t]{2}{*}{7} & 121 & 1.72 & $28.4 \pm 0$ & \multirow[t]{2}{*}{0.0009} & \multirow[t]{2}{*}{ Positive } \\
\hline & & & & others & 98.28 & $23.0 \pm 0.3$ & & \\
\hline \multirow[t]{2}{*}{ TGW } & \multirow[t]{2}{*}{$4 \mathrm{~A}$} & \multirow[t]{2}{*}{ Xgwm397 } & \multirow[t]{2}{*}{18} & 190 & 0.86 & $21.7 \pm 0$ & \multirow[t]{2}{*}{0.0001} & \multirow[t]{2}{*}{ Negative } \\
\hline & & & & others & 99.14 & $32.2 \pm 0.43$ & & \\
\hline \multirow[t]{2}{*}{ GYP } & \multirow[t]{2}{*}{$4 \mathrm{~B}$} & \multirow[t]{2}{*}{ Xgwm165 } & \multirow[t]{2}{*}{28} & 191 & 78.44 & $768.6 \pm 26.3$ & \multirow[t]{2}{*}{0.0010} & \multirow[t]{2}{*}{ Positive } \\
\hline & & & & others & 21.56 & $652 \pm 54.34$ & & \\
\hline \multirow[t]{2}{*}{ TGW } & \multirow[t]{2}{*}{$4 \mathrm{~B}$} & \multirow[t]{2}{*}{ Xgwm149 } & \multirow[t]{2}{*}{31} & 139 & 0.86 & $35.34 \pm 0$ & \multirow[t]{2}{*}{0.0003} & \multirow[t]{2}{*}{ Positive } \\
\hline & & & & others & 99.14 & $32.6 \pm 0.4$ & & \\
\hline
\end{tabular}

Note. DS: drought stress; WW: well-watered; Chr. chromosome; DTH: days to heading; TGWG: thousand-grain weight at grain filling stage; LIBSIT: length of internodes below second internode from the top; PH: plant height; SWSCG: stem water-soluble carbohydrates at grain filling stage; PL: peduncle length; SWSCF: stem water-soluble carbohydrates at flowering stage; TGW: thousand-grain weight; SP: number of spikes per plant; CCG: chlorophyll content at grain filling; GY: grain yield per plant; LSIT: length of second internode from the top; GYP: grain yield per plot.

On chromosome 2D, four traits such as GY (DS), LIBSIT (DS and WW), PH (DS) and SWSCG (DS) were tagged by SSR markers $X w m c 25(18 \mathrm{cM})$ and $X w m c 112(28 \mathrm{cM})$. The LIBSIT (DS and WW) and TGWG (DS) were associated by Xgwm $285(61 \mathrm{cM})$ and Xbarc164 $(70 \mathrm{cM})$ on chromosome 3B. LIBSIT (DS), LSIT (DS and WW), PH (DS), PL (DS), SWSCF (DS), TGW (WW) were tagged by the Xwmc420 (7 cM) and Xgwm397 (18 $\mathrm{cM})$ on chromosome 4A. Xbarc78 $(71 \mathrm{cM})$ was associated with PH and LIBSIT also on chromosome 4A in both water conditions. On chromosome 4B, SP (DS) and TGW (DS and WW) and GYP (WW) were identified by markers Xgwm149 (31 cM) and Xgwm165 (28 cM). The LIBSIT, TGWG and TGW were separately tagged by three markers Xgwm293 (52 cM), Xgwm415 (56 cM) and Xgwm304 (61 cM) on chromosome 5A under DS condition.

\subsection{Favorable Alleles for Different Traits}

Four of the 17 loci had significantly favorable allelic effect on multiple traits were identified in DS and WW conditions (Table 3). Most of the traits had $<5 \%$ frequency of the SSR marker allele in both conditions. It was considered as a rare allele. Under DS condition, 163 bp allele of Xbarc78 on chromosome 4A (Xbarc78-4A 163 ) showed positive effects on LIBSIT and PH, respectively. This allele had a frequency of $5.17 \%$ on both traits. Under WW condition, two marker alleles Xwmc 25-2D $D_{151}$ and $X g w m 165-4 B_{191}$ separately increased GY and GYP, but $X$ barc $78-4 A_{155}$ showed a negative effect on $\mathrm{PH}$. These favorable alleles associated with important traits that could be contribute to increase wheat production in different water environments.

\section{Discussion}

\subsection{Variation of Stem Water-Soluble Carbohydrates under Different Water Condition}

The stem WSCs become more important for grain yield in cereal crops under abiotic stress (Blum, 1998; Kiniry, 1993; van Herwaarden et al., 1998). A good capacity for stem reserve and remobilization of WSC has been proposed as a drought adaptive trait in a conceptual model for drought tolerance (Reynolds, 1999). In this study, variation in SWSC among 116 genotypes at two developmental stages has been observed under two water regimes. The phenotypic means for this trait were more affected by drought stress. The means under drought stress were significantly higher than those under well-watered. The present observations were consistent with the view of Zhang et al. (2014) that reported fructan synthesis is induced by drought stress, and that drought tolerant plants can manufacture more fructans. Fructans are the major component of WSC, insert between the head groups of phospholipids, acting as compatible solutes in cells to protect cell membranes and proteins from osmotic damage (Rathinasabapathi, 2000; Vereyken et al., 2001).

In our research, SWSCF and SWSCG under drought stress were overall higher than those under well-watered condition. The tolerant cultivars activate their protection mechanisms faster and more efficiently than the sensitive ones to cope with stress conditions (Goggin \& Setter, 2004; Gupta et al., 2011). WSC mobilizes from the stem during the later phase of grain filling and thus can become an important source of assimilate for grain yield in wheat under terminal drought stress conditions (Blum, 1998). Stem WSC accumulation is influenced by 
environmental factors (Blum, 1998; Ruuska et al., 2008; Ruuska et al., 2006). However, considerable genotypic variation in stem WSC concentration has been observed in wheat (Ruuska et al., 2006; Xue et al., 2008).

\subsection{Heritability of Stem Water-Soluble Carbohydrates}

In the present study, moderate to high broad sense heritability for SWSC at two stages (flowering and grain filling) under WW and DS conditions were estimated ranged from $0.76 \sim 0.78$ to $0.71 \sim 0.80$. High heritability indicates potential for phenotypic selection of WSC among families in breeding programs that target adaptation to terminal droughts (Rebetzke et al., 2007). The ability to store and remobilize large amounts of WSC to grain has been suggested as a selection criterion for wheat breeding due to its high heritability and positive linear ship with grain yield (Dreccer et al., 2009; Gupta et al., 2011).

\subsection{Correlation of Stem Water-Soluble Carbohydrates and Grain Yield Traits}

Mobilization of WSC during grain filling can potentially contribute about $20 \%$ of the final grain weight under non-stress conditions, and up to $70 \%$ or more of grain dry matter under drought stress in wheat (Goggin \& Setter, 2004). It has also been reported that stem WSC concentration at anthesis or shortly after anthesis (i.e. at the stem WSC accumulation phase) is a good indicator of positive association between WSC level and grain weight or yield in wheat (Foulkes et al., 2007). Our research exhibited that SWSCF showed significantly negative correlation with AESWSC while positive association with TGWG and TGWM under both normal and stress conditions. In contrast, SWSCG had significant correlation with all traits such as AESWSC, TGWG, TGWM, GFEE and GFEL under both conditions with the exception of TGWG under WW condition that reflected non-significant association between SWSCG and TGWG. It is suggested that SWSCG could play a key function in the subsequent release of carbohydrates from stem to grain. Current results are in conformity by Yang et al. (2007). WSC are recognized as an important source of grain dry matter for grain filling, especially when current photosynthesis is inhibited by drought stress. Water deficit during grain filling stimulates senescence of the whole plant and enhances mobilization of reserved WSC to the grains (Araus et al., 2002; Guoth et al., 2009).

Negative correlation was observed between SWSCG and GFEE, whereas there was a positive association of SWSCG with GFEL under both environments. It is suggested that SWSCG could play an important role in grain filling of wheat. AESWSC exhibited positive correlation with TGWM and GFEL in both drought stress and well-watered conditions. It indicated that accumulation of water-soluble carbohydrates increased the grain filling efficiency at the later stages and that contributed to heavier the grains in term of thousand-grain weight. Xue et al. (2008) also reported a positive and significant relationship with WSC and grain weight in wheat lines.

In this study, thousand-grain weight and grain filling efficiency under drought stress was slightly lower than those under well-watered condition during the early grain filling period. Li et al. (2015) reported higher thousand-grain weight with increased grain filling efficiency under drought stress as compared to well-watered condition during the early grain filling period. Water deficit at grain filling induces carbon mobilization from tillers to the main stem ear (Blum et al., 1994). Rebetzke et al. (2007) reported that wheat progeny with high WSC produced higher grain weight and larger diameter, significantly reducing grain shriveling. WSC accumulation and remobilization are influenced by many factors, making the relationship between WSC and TGW more complex.

\subsection{Genetic Polymorphism}

A total of 1600 alleles were identified from 92 SSR loci when scored on 116 genotypes. High levels of polymorphism were observed for the markers, with a range of 3 49 and average of 17.39 alleles per marker locus, which indicated that the diversity of wheat accessions in this study was relatively high. The microsatellite markers presented high level of PIC in comparison with other markers in wheat (Gupta et al., 2008). It is suggested that genomic SSR markers is powerful for the evaluation of genetic polymorphism, similar results were obtained in 103 wheat accessions (Liu et al., 2010).

\subsection{Marker Allele-Trait Associations}

\subsubsection{Chromosome 4A}

We identified 17 SSR marker loci which significantly associated with agronomic and physiological traits. Among them, chromosome $4 \mathrm{~A}$ was most important, six traits were associated with three loci, including Xwmc 420-4A (7 cM), Xgwm397-4A (18 cM) and Xbarc78-4A $(71 \mathrm{cM})$. Four classes of marker pairs were defined on the basis of the map positions determined by Marone et al. (2012): class 1 (tight linkage; distance, $<10 \mathrm{cM}$ ); class 2 (moderate linkage; distance, 10 20 cM); class 3 (loosely linked; distance, 20 50 cM); and class 4 (independent pairs; distance, $>50 \mathrm{cM}$ ). It is suggested that Xwmc420 and Xgwm397 moderately linked however Xbarc 78 behaved as an independent locus. 
The present research results indicated that Xwmc420-4A was associated with LSIT under both drought stress and well-watered conditions, and also associated with LIBSIT, PH, PL, and SWSCF in drought stress. Xwmc89, a marker locus at the same position as Xwmc420, was reported that significantly associated with all grain related QTLs and explained the high proportion of phenotypic variation (Kirigwi et al., 2007). A SSR marker Xwmc48 was identified associating with QTL for grain yield (Kirigwi et al., 2007). In addition, Liu et al. (2010) identified a QTL for PH nearby marker Xwmc420. In current study, Crossa et al. (2007) found a DArT marker wPt8271, which close to Xbarc70 and Xbarc78, was associated with GY, whereas Liu et al. (2010) reported for grains per spike and thousand-kernel weight.

\subsubsection{Chromosome 5A}

The next important chromosome in this research was 5A. It was tagged by three SSR markers namely Xgwm293 $(52 \mathrm{cM}), \mathrm{Xgwm} 415(56 \mathrm{cM})$ and $\mathrm{Xgwm} 304(61 \mathrm{cM})$. The distance among these markers were less than $10 \mathrm{cM}$. Yang et al. (2007) detected QTL with flanking marker of Xwmc524 Xgwm595 for TGWG, it was on the same chromosome as our studies but with different position and also was associated with same trait as in this study. Furthermore, (Maccaferri et al., 2011) found Xbarc197 located on chromosome 5A (53 cM) adjacent with Xgwm293 (52 cM) and also nearby Xgwm415 and Xgwm304 (56 and $61 \mathrm{cM}$ apart), was associated with grain yield using association analysis. In our study, Xgwm293, Xgwm415 and Xgwm304 were associated with LIBSIT and TGWG and TGW under DS, while TGW is one of the most important factors affecting grain yield.

\subsubsection{Chromosome 2D}

Chromosome 2D is important for yield and yield components and also for stem water-soluble carbohydrates. Three SSR markers i.e. Xwmc25 (18 cM), Xwmc112 (28 cM) and Xgwm382 (100 cM) were associated with GY (WW), PH (DS), LIBSIT (DS and WW), SWSCG (DS) and CCG (WW). The distance between two markers were $10 \mathrm{cM}$ so it could be considered as moderately linked according to the classification of Marone et al. (2012) however Xgwm382 was away from these markers. It acted as an independent marker. A marker Xcfd17 associated with WSC under WW with $64 \mathrm{cM}$ was apart from our finding but on the same chromosome 2D (Zhang et al., 2014).

In addition to this, $\mathrm{Li}$ et al. (2015) detected a marker Xgwm261-2D was on $23 \mathrm{cM}$ and it was nearby a marker $X w m c 112-2 D(28 \mathrm{cM})$ was associated with SWSCG under terminal DS. The distance of these two markers was close and also was associated with the same trait. This finding was strengthened by our result. According to Rebetzke et al. (2007), the QTL on chromosome 2D was also mapped for WSC. It was also supported by Yang et al. (2007), but they reported QTL for WSC away from those markers that we found, and also it was reported at flowering stage. Dodig et al. (2012) identified SSR marker Xgwm484 (41 cM) for chlorophyll content at grain filling but far distance from that marker we reported. In current study, Xgwm382 was located at $100 \mathrm{cM}$ and associated with chlorophyll content at grain filling under well-watered condition.

\subsubsection{Chromosome 4B}

Chromosome 4B were tagged by two SSR markers i.e. Xgwm149 (31 cM) and Xgwm165 (28 cM) were associated with SP (DS), TGW (DS and WW) and GYP (WW). These two markers are tightly linked with each other. In the present study, Xgwm149 was associated with SP (DS) and TGW in both environments whereas Xgwm 165 was associated with GYP under WW condition only while SP, TGW and GYP are the most important traits that affecting grain yield. A QTL was reported for TGW under post-anthesis drought stress on chromosome 4BL (Nezhad et al., 2012).

\subsubsection{Chromosome 3B}

We detected that Xgwm285 $(61 \mathrm{cM})$ and Xbarc164 $(70 \mathrm{cM})$ tightly linked with each other. They were associated with LIBSIT (DS and WW) and TGWG (DS) on chromosome 3BL. Whereas Xgwm389 was associated with tiller number on 3BS (Dodig et al., 2010).

\subsubsection{Chromosome 1A}

In our study, identified a marker Xbarc148 (57 cM) was associated with DTH (DS) on chromosome 1A. A QTL for GY was mapped on chromosome 1A (Quarrie et al., 2005). A marker Xgwm99 (126 cM) was reported associating with GY on chromosome 1A (Dodig et al., 2012).

\subsubsection{Chromosome 1D}

We identified that Xwmc432-1D (23 cM) was associated with TGWG under DS. An SSR locus Xgwm337 (48 cM) was associated with GW on the same chromosome but far from Xwmc432 (Groos et al., 2003). A QTL for lodging resistance was reported on chromosome 1D in a wheat DH population (Verma et al., 2005). 


\subsubsection{Chromosome 2A}

Marker Xwmc296 (49 cM) on chromosome 2A was associated with LIBSIT in WW condition. It was detected QTL for PL on the same chromosome with different SSR marker Xgwm294 (76 cM) (Brbaklić et al., 2015).

\subsubsection{Chromosome 7D}

In an interval map of $77 \mathrm{cM}$ on chromosome arm 7DS, SSR marker Xgwm295 was identified for TGWG in DS. Previously reported QTL linked with TGW under terminal drought stress that close to Xgwm295 marker (Nezhad et al., 2012).

\subsection{Favorable Alleles for Different Traits}

Xbarc 78-4A was associated with LIBSIT and PH under DS, however it was only associated with PH under WW condition. It was considered as favorable alleles for these two traits. For well-watered condition, two favorable alleles were also identified on chromosome 2D and 4B that associated with GY and GYP. These traits are important for the contribution to improve the production of wheat.

\section{Conclusions}

It is inferred that SWSC were accumulated more at grain filling stage in DS and it is considered as increase fructans for self-protection. High heritability estimated for SWSCG under drought stress. The ability to accumulate WSC and high heritability in grain filling stage suggested as a selection criterion for wheat breeding. Total of seventeen significant marker-trait associations for 13 traits were detected. Chromosomes 2D, 4A and 5A are the most important with respect to traits and loci distance. Xwmc25, Xwmc112 and Xgwm382 were associated with GY (WW), PH (DS), SWSCG (DS) and CCG (WW). The next is 4A found two markers i.e. Xwmc420 and Xgwm397 are moderately linked with each other. Xwmc420 was associated with PH, PL and SWSCF for DS, whereas $\mathrm{Xgwm} 397$ was associated with TGW for WW condition. Another chromosome is 5A, three SSR markers namely Xgwm293, Xgwm 415 and Xgwm304 were associated with TGW under DS.

Four favorable alleles were identified in two water environments, including $X b a r c 78-4 A_{163}$ increasing plant height in drought stress, but $X$ barc $78-4 A_{155}$ decreased plant height under well-watered condition. $X w m c 25-2 D_{15 I}$ and $X g w m 165-4 B_{191}$ were considered as favorable alleles for increasing grain yield under well-watered condition. All these markers are firstly reported with the traits in our study and expected to be helpful for marker assisted selection in wheat improvement.

\section{Acknowledgements}

The research funding supported by the National Natural Science Foundation of China (31461143024, 31271720), and the National High-tech R\&D Program of China (2011AA100501).

\section{References}

Alexandratos, N., \& Bruinsma, J. (2012). World Ariculture Towards 2030/2050 (The 2012 Revision). Agricultural Development Economics Division. Food and Agriculture Organization of the United Nations. Viale delle Terme di Caracalla 00153 Rome, Italy. Retrieved from http://www.fao.org/docrep/016/ ap106e/ap106e

Araus, J. L., Slafer, G., Reynolds, M., \& Royo, C. (2002). Plant breeding and drought in C3 cereals: what should we breed for? Annals of Botany, 89, 925-940. http://dx.doi.org/10.1093/aob/mcf049

Araus, J. L., Bort, J., Steduto, P., Villegas, D., \& Royo, C. (2003). Breeding cereals for Mediterranean conditions: Ecophysiology clues for biotechnology application. Ann. Appl. Biol., 142, 129-141. http://dx.doi.org/ 10.1111/j.1744-7348.2003.tb00238.x

Blum, A. (1998). Improving wheat grain filling under stress by stem reserve mobilisation. Euphytica, 100, 77-83. http://dx.doi.org/10.1023/A:1018303922482

Blum, A., Sinmena, B., Mayer, J., Golan, G., \& Shpiler, L. (1994). Stem reserve mobilisation supports wheat-grain filling under heat stress. Australian Journal of Plant Physiology, 21, 771-781. http://dx.doi.org/10.1071/PP9940771

Botstein, D., White, R. L., Skolnick, M., \& Davis, R. W. (1980). Construction of a genetic linkage map in man using restriction fragment length polymorphisms. American Journal of Human Genetics, 32, 314-331. Retrieved from http://www.ncbi.nlm.nih.gov/pubmed/6247908 
Bradbury, P. J., Zhang, Z., Kroon, D. E., Casstevens, T. M., Ramdoss, Y., \& Buckler, E. S. (2007). TASSEL: software for association mapping of complex traits in diverse samples. Bioinformatics, 23, 2633-2635. http://dx.doi.org/10.1093/bioinformatics/btm308

Brbaklić, L., Trkulja, D., Kondić-Špika, A., Hristov, N., Denčić, S., Mikić, S., \& Kobiljski, B. (2015). Genetic associations in the detection of QTLs for wheat spike-related traits. Pesquisa Agropecuária Brasileira, 50, 149-159. http://dx.doi.org/10.1590/S0100-204X2015000200007

Collins, N. C., Tardieu, F., \& Tuberosa, R. (2008). Quantitative trait loci and crop performance under abiotic stress: where do we stand? Plant Physiology, 147, 469-486. http://dx.doi.org/10.1104/pp.108.118117

Cooper, M., van Eeuwijk, F. A., Hammer, G. L., Podlich, D. W., \& Messina, C. (2009). Modeling QTL for complex traits: detection and context for plant breeding. Current Opinion in Plant Biology, 12, 231-240. http://dx.doi.org/10.1016/j.pbi.2009.01.006

Crossa, J., Burgueno, J., Dreisigacker, S., Vargas, M., Herrera-Foessel, S. A., Lillemo, M., \& Franco, J. (2007). Association analysis of historical bread wheat germplasm using additive genetic covariance of relatives and population structure. Genetics, 177, 1889-1913. http://dx.doi.org/10.1534/genetics.107.078659

Dodig, D., Zoric, M., Kobiljski, B., Savic, J., Kandic, V., Quarrie, S., \& Barnes, J. (2012). Genetic and association mapping study of wheat agronomic traits under contrasting water regimes. International Journal of Molecular Sciences, 13, 6167-6188.http://dx.doi.org/10.3390/ijms13056167

Dodig, D., Zorić, M., Kobiljski, B., Šurlan-Momirović, G., \& Quarrie, S. A. (2010). Assessing drought tolerance and regional patterns of genetic diversity among spring and winter bread wheat using simple sequence repeats and phenotypic data. Crop and Pasture Science, 61, 812-824. http://dx.doi.org/10.1071/CP10001

Dreccer, M. F., van Herwaarden, A. F., \& Chapman, S. C. (2009). Grain number and grain weight in wheat lines contrasting for stem water soluble carbohydrate concentration. Field Crops Research, 112, 43-54. http://dx.doi.org/10.1016/j.fcr.2009.02.006

Foulkes, M., Sylvester-Bradley, R., Weightman, R., \& Snape, J. (2007). Identifying physiological traits associated with improved drought resistance in winter wheat. Field Crops Research, 103, 11-24. http://dx.doi.org/10.1016/j.fcr.2007.04.007

Gebbing, T. (2003). The enclosed and exposed part of the peduncle of wheat (Triticum aestivum)-spatial separation of fructan storage. New Phytologist, 159, 245-252. http://dx.doi.org/10.1046/j.1469-8137. 2003.00799.x

Gebbing, T., \& Schnyder, H. (1999). Pre-anthesis reserve utilization for protein and carbohydrate synthesis in grains of wheat. Plant Physiology, 121, 871-878. http://dx.doi.org/10.1104/pp.121.3.871

Goggin, D. E., \& Setter, T. L. (2004). Fructosyltransferase activity and fructan accumulation during development in wheat exposed to terminal drought. Functional Plant Biology, 31, 11-21. http://dx.doi.org/ 10.1071/FP03123

Groos, C., Robert, N., Bervas, E., \& Charmet, G. (2003). Genetic analysis of grain protein-content, grain yield and thousand-kernel weight in bread wheat. Theoretical and Applied Genetics, 106, 1032-1040. http://dx.doi.org/10.1007/s00122-002-1111-1

Guoth, A., Tari, I., Galle, A., Csiszar, J., Pecsvaradi, A., Cseuz, L., \& Erdei, L. (2009). Comparison of the drought stress responses of tolerant and sensitive wheat cultivars during grain filling: Changes in flag leaf photosynthetic activity, ABA levels, and grain yield. Journal of Plant Regulation, 28, 167-176. http://dx.doi.org/10.1007/s00344-009-9085-8

Gupta, A. K., Kaur, K., \& Kaur, N. (2011). Stem reserve mobilization and sink activity in wheat under drought conditions. American Journal of Plant Sciences, 2, 70-77. http://dx.doi.org/10.4236/ajps.2011.21010

Gupta, P., Balyan, H., Edwards, K., Isaac, P., Korzun, V., Röder, M., \& Dubcovsky, J. (2002). Genetic mapping of 66 new microsatellite (SSR) loci in bread wheat. Theoretical and Applied Genetics, 105, 413-422. http://dx.doi.org/10.1007/s00122-002-0865-9

Gupta, S., Srivastava, M., Mishra, G., Naik, P., Chauhan, R., Tiwari, S., \& Singh, R. (2008). Analogy of ISSR and RAPD markers for comparative analysis of genetic diversity among different Jatropha curcas genotypes. African Journal of Biotechnology, 7, 4230-4243. Retrieved from http://www.ajol.info/index.php/ ajb/article/view/59558/47849 
Guyomarc'h, H., Sourdille, P., Charmet, G., Edwards, K., \& Bernard, M. (2002). Characterisation of polymorphic microsatellite markers from Aegilops tauschii and transferability to the D-genome of bread wheat. Theoretical and Applied Genetics, 104, 1164-1172. http://dx.doi.org/10.1007/s00122-001-0827-7

Kang, H. M., Zaitlen, N. A., Wade, C. M., Kirby, A., Heckerman, D., Daly, M. J., \& Eskin, E. (2008). Efficient control of population structure in model organism association mapping. Genetics, 178, 1709-1723. http://dx.doi.org/10.1534/genetics.107.080101

Kiniry, J. (1993). Non structural carbohydrate utilization by wheat shaded during grain growth. Agronomy Journal, 85, 844-849.

Kirigwi, F., Van Ginkel, M., Brown-Guedira, G., Gill, B., Paulsen, G., \& Fritz, A. (2007). Markers associated with a QTL for grain yield in wheat under drought. Molecular Breeding, 20, 401-413. http://dx.doi.org/0.1007/s11032-007-9100-3

Li, W., Zhang, B., Li, R., Chang, X., \& Jing, R. (2015). Favorable alleles for stem water-soluble carbohydrates identified by association analysis contribute to grain weight under drought stress conditions in wheat. PLoS ONE, 10, e0119438. http://dx.doi.org/10.1371/journal.pone.0119438

Liu, K., \& Muse, S. V. (2005). PowerMarker: An integrated analysis environment for genetic marker analysis. Bioinformatics, 21, 2128-2129. http://dx.doi.org/10.1093/bioinformatics/bti282

Liu, L., Wang, L., Yao, J., Zheng, Y., \& Zhao, C. (2010). Association mapping of six agronomic traits on chromosome 4A of wheat (Triticum aestivum L.). Molecular Plant Breeding, 5, 1-10. http://dx.doi.org/10.5376/mpb.2010.01.0005

Maccaferri, M., Sanguineti, M. C., Demontis, A., El-Ahmed, A., Garcia del Moral, L., Maalouf, F., \& Tuberosa, R. (2011). Association mapping in durum wheat grown across a broad range of water regimes Journal of Experimental Botany, 62, 409-438. http://dx.doi.org/10.1093/jxb/erq287

Marone, D., Laidò, G., Gadaleta, A., Colasuonno, P., Ficco, D. B., Giancaspro, A., \& De Vita, P. (2012). A high-density consensus map of A and B wheat genomes. Theoretical and Applied Genetics, 125, 1619-1638. http://dx.doi.org/10.1007/s00122-012-1939-y

McIntyre, C. L., Seung, D., Casu, R. E., Rebetzke, G. J., Shorter, R., \& Xue, G. P. (2012). Genotypic variation in the accumulation of water soluble carbohydrates in wheat. Functional Plant Biology, 39, 560-568. http://dx.doi.org/10.1071/FP12077

Nagata, K., Shimizu, H., \& Terao, T. (2002). Quantitative trait loci for nonstructural carbohydrate accumulation in leaf sheaths and culms of rice (Oryza sativa L.) and their Effects on Grain Filling. Breeding Science, 52, 275-283. http://dx.doi.org/10.1270/jsbbs.52.275

Nezhad, K. Z., Weber, W., Röder, M., Sharma, S., Lohwasser, U., Meyer, R., \& Börner, A. (2012). QTL analysis for thousand-grain weight under terminal drought stress in bread wheat (Triticum aestivum L.). Euphytica, 186, 127-138. http://dx.doi.org/10.1007/s10681-011-0559-y

Pritchard, J. K., Stephens, M., \& Donnelly, P. (2000). Inference of population structure using multilocus genotype data. Genetics, 155, 945-959. Retrieved from http://www.stats.ox.ac.uk/ pritch/home.html

Quarrie, S. A., Steed, A., Calestani, C., Semikhodskii, A., Lebreton, C., Chinoy, C., \& Dodig, D. (2005). A high-density genetic map of hexaploid wheat (Triticum aestivum L.) from the cross Chinese Spring x SQ1 and its use to compare QTLs for grain yield across a range of environments. Theoretical Applied Genetics, 110, 865-80. http://dx.doi.org/10.1007/s00122-004-1902-7

Rathinasabapathi, B. (2000). Metabolic engineering for stress tolerance: Installing osmoprotectant synthesis pathways. Annals of Botany, 86, 709-716. http://dx.doi.org/10.1006/anbo.2000.1254

Rebetzke, G., Van Herwaarden, A., Jenkins, C., Ruuska, S., Tabe, L., Fettell, N., \& Richards, R. (2007). Genetic control of water-soluble carbohydrate reserves in bread wheat. In H. T. Buck, J. E. Nisi, \& N. Salomon (Eds.), Wheat Production in Stressed Environments. Proceedings of the $7^{\text {th }}$ International Wheat Conference, 27 November-2 December 2005, Mar del Plata, Argentina (pp. 349-356). Springer, The Netherlands. http://dx.doi.org/10.1007/1-4020-5497-1_43

Rebetzke, G., Van Herwaarden, A., Jenkins, C., Weiss, M., Lewis, D., Ruuska, S., \& Richards, R. (2008). Quantitative trait loci for water-soluble carbohydrates and associations with agronomic traits in wheat. Crop and Pasture Science, 59, 891-905. http://dx.doi.org/10.1071/AR08067 
Reynolds, M. P., Skovmand, B., Trethowan, R., \& Pfeiffer, W. (1999). Evaluating a conceptual model model for drought tolerance. In J.-M. Ribaut, \& D. Poland (Eds.), Molecular approaches for Genetic Improvement of Cereals for Stable Production in Water-Limited Environments: a strategic planning workshop (pp. 49-53). El-Batan, Mexico, CIMMYT.

Röder, M. S., Korzun, V., Wendehake, K., Plaschke, J., Tixier, M. H., Leroy, P., \& Ganal, M. W. (1998). A microsatellite map of wheat. Genetics, 149, 2007-2023. Retrieved from http://www.ncbi.nlm.nih.gov/ pmc/articles/PMC1460256

Ruuska, S. A., Lewis, D. C., Kennedy, G., Furbank, R. T., Jenkins, C. L., \& Tabe, L. M. (2008). Large scale transcriptome analysis of the effects of nitrogen nutrition on accumulation of stem carbohydrate reserves in reproductive stage wheat. Plant Molecular Biology, 66, 15-32. http://dx.doi.org/10.1007/s11103-0079249-5

Ruuska, S. A., Rebetzke, G. J., van Herwaarden, A. F., Richards, R. A., Fettell, N. A., Tabe, L., \& Jenkins, C. L. (2006). Genotypic variation in water-soluble carbohydrate accumulation in wheat. Functional Plant Biology, 33, 799-809. http://dx.doi.org/10.1071/FP06062

Song, Q., Shi, J., Singh, S., Fickus, E., Costa, J., Lewis, J., \& Cregan, P. (2005). Development and mapping of microsatellite (SSR) markers in wheat. Theoretical and Applied Genetics, 110, 550-560. http://dx.doi.org/ 10.1007/s00122-004-1871-x

Sorrells, M. E., \& Yu, J. (2009). Linkage disequilibrium and association mapping in the Triticeae. In C. Feuillet \& G. J. Muehlbaucer (Eds.), Genetics and Genomics of the Triticeae (pp. 655-683). Springer, Gatersleben, Germany.

Sourdille, P., Tavaud, M., Charmet, G., \& Bernard, M. (2001). Transferability of wheat microsatellites to diploid Triticeae species carrying the A, B and D genomes. Theoretical and Applied Genetics, 103, 346-352. http://dx.doi.org/10.1007/s00122-001-0542-4

Takai, T., Fukuta, Y., Shiraiwa, T., \& Horie, T. (2005). Time-related mapping of quantitative trait loci controlling grain-filling in rice (Oryza sativa L.). Journal of Experimental Botany, 56, 2107-2118. http://dx.doi.org/10.1093/jxb/eri209

Teulat, B., Borries, C., \& This, D. (2001). New QTLs identified for plant water status, water-soluble carbohydrate and osmotic adjustment in a barley population grown in a growth-chamber under two water regimes. Theoretical and Applied Genetics, 103, 161-170. http://dx.doi.org/10.1007/s001220000503

Thévenot, C., Simond-Côte, E., Reyss, A., Manicacci, D., Trouverie, J., Le Guilloux, M., \& Prioul, J. L. (2005). QTLs for enzyme activities and soluble carbohydrates involved in starch accumulation during grain filling in maize. Journal of Experimental Botany, 56, 945-958. http://dx.doi.org/10.1093/jxb/eri087

Tuberosa, R., \& Salvi, S. (2006). Genomics-based approaches to improve drought tolerance of crops. Trends in Plant Science, 11, 405-412. http://dx.doi.org/10.1016/j.tplants.2006.06.003

Turner, L. B., Cairns, A. J., Armstead, I. P., Ashton, J., Skøt, K., Whittaker, D., \& Humphreys, M. O. (2006). Dissecting the regulation of fructan metabolism in perennial ryegrass (Lolium perenne) with quantitative trait locus mapping. New Phytologist, 169, 45-57. http://dx.doi.org/10.1111/j.1469-8137.2005.01575.x

USDA. (2016). World Agricultural Production. Washington, DC. Retrieved from http://apps.fas.usda.gov/ psdonline/circulars/production.pdf

van Herwaarden, A., Angus, J., Richards, R., \& Farquhar, G. (1998). 'Haying-off', the negative grain yield response of dryland wheat to nitrogen fertiliser III. The influence of water deficit and heat shock. Australian Journal of Agricultural Research, 49, 1095-1110. http://dx.doi.org/10.1071/A97041

Vereyken, I. J., Chupin, V., Demel, R. A., Smeekens, S. C., \& De Kruijff, B. (2001). Fructans insert between the headgroups of phospholipids. Biochimica et Biophysica Acta (BBA)-Biomembranes, 1510, 307-320. http://dx.doi.org/10.1016/S0005-2736(00)00363-1

Verma, V., Worland, A., Savers, E., Fish, L., Caligari, P., \& Snape, J. (2005). Identification and characterization of quantitative trait loci related to lodging resistance and associated traits in bread wheat. Plant Breeding, 124, 234-241. http://dx.doi.org/10.1111/j.1439-0523.2005.01070.x

Wang, Z., Liu, X., Li, R., Chang, X., \& Jing, R. (2011). Development of near-infrared reflectance spectroscopy models for quantitative determination of water-soluble carbohydrate content in wheat stem and glume. Analytical Letters, 44, 2478-2490. http://dx.doi.org/10.1080/00032719.2011.551859 
Waugh, R., Jannink, J. L., Muehlbauer, G. J., \& Ramsay, L. (2009). The emergence of whole genome association scans in barley. Current Opinion in Plant Biology, 12, 218-222. http://dx.doi.org/10.1016/ j.pbi.2008.12.007

Xue, G. P., McIntyre, C. L., Jenkins, C. L., Glassop, D., van Herwaarden, A. F., \& Shorter, R. (2008). Molecular dissection of variation in carbohydrate metabolism related to water-soluble carbohydrate accumulation in stems of wheat. Plant Physiology, 146, 441-454. http://dx.doi.org/10.1104/pp.107.113076

Yang, D. L., Jing, R. L., Chang, X. P., \& Li, W. (2007). Identification of quantitative trait loci and environmental interactions for accumulation and remobilization of water-soluble carbohydrates in wheat (Triticum aestivum L.) stems. Genetics, 176, 571-584. http://dx.doi.org/10.1534/genetics.106.068361

Yang, J., \& Zhang, J. (2006). Grain filling of cereals under soil drying. New Phytologist, 169, 223-236. http://dx.doi.org/10.1111/j.1469-8137.2005.01597.x

Yu, J., Pressoir, G., Briggs, W. H., Bi, I. V., Yamasaki, M., Doebley, J. F., \& Holland, J. B. (2006). A unified mixed-model method for association mapping that accounts for multiple levels of relatedness. Nature Genetics, 38, 203-208. http://dx.doi.org/10.1038/ng1702

Zhang, B., Li, W., Chang, X., Li, R., \& Jing, R. (2014). Effects of favorable alleles for water-soluble carbohydrates at grain filling on grain weight under drought and heat stresses in wheat. PLOS ONE, 9, e102917. http://dx.doi.org/10.1371/journal.pone.0102917

Zhang, J., Dell, B., Ma, W., Vergauwan, R., Zhang, X., Oteri, T., \& Van den Ende, W. (2016). Contribution of root WSC during grain filling in wheat under drought. Frontiers in Plant Science, 7, http://dx.doi.org/10.3389/fpls.2016.00904

\section{Appendix}

Appendix 1. Descriptive statistics and broad sense heritability $\left(h_{\mathrm{B}}^{2}\right)$ for agronomical and physiological traits under both DS and WW conditions

\begin{tabular}{|c|c|c|c|c|c|}
\hline Traits & Water regimes & Mean \pm SD & Range & CV (\%) & $h_{\mathrm{B}}^{2}$ \\
\hline \multirow[t]{2}{*}{ DTH } & DS & $209 \pm 3.09$ & $200 \sim 219$ & 0.01 & 0.36 \\
\hline & WW & $213 \pm 3.42$ & $204 \sim 224$ & 0.02 & 0.39 \\
\hline \multirow[t]{2}{*}{ DTF } & $\mathrm{DS}$ & $217 \pm 2.63$ & $209 \sim 224$ & 0.01 & 0.42 \\
\hline & WW & $222 \pm 3.13$ & $213 \sim 231$ & 0.01 & 0.53 \\
\hline \multirow[t]{2}{*}{$\mathrm{CCF}$} & DS & $52.20 \pm 4.18$ & $36.80 \sim 64.34$ & 0.08 & 0.81 \\
\hline & WW & $55.20 \pm 3.94$ & $43.84 \sim 66.64$ & 0.07 & 0.78 \\
\hline \multirow[t]{2}{*}{ CCG } & DS & $44.36 \pm 6.83$ & $2.80 \sim 60.24$ & 0.15 & 0.59 \\
\hline & WW & $40.28 \pm 9.34$ & $6.44 \sim 58.38$ & 0.23 & 0.72 \\
\hline \multirow[t]{2}{*}{ FLA } & $\mathrm{DS}$ & $9.79 \pm 2.06$ & $5.87 \sim 16.82$ & 0.21 & 0.37 \\
\hline & WW & $14.0 \pm 3.14$ & 7.81 28.77 & 0.22 & 0.30 \\
\hline \multirow[t]{2}{*}{$\mathrm{PH}$} & $\mathrm{DS}$ & $76 \pm 15.66$ & $36 \sim 118$ & 0.21 & 0.80 \\
\hline & WW & $100 \pm 20.26$ & $50 \sim 142$ & 0.20 & 0.93 \\
\hline \multirow[t]{2}{*}{$\mathrm{SP}$} & $\mathrm{DS}$ & $10 \pm 2.63$ & $4 \sim 21$ & 0.26 & 0.91 \\
\hline & WW & $12 \pm 2.80$ & $6 \sim 24$ & 0.23 & 0.88 \\
\hline \multirow[t]{2}{*}{$\mathrm{SL}$} & $\mathrm{DS}$ & $8.10 \pm 1.03$ & $5.40 \sim 10.60$ & 0.13 & 0.97 \\
\hline & WW & $8.68 \pm 1.23$ & $5.00 \sim 12.30$ & 0.14 & 0.97 \\
\hline \multirow[t]{2}{*}{$\mathrm{PL}$} & $\mathrm{DS}$ & $21.32 \pm 4.73$ & $11.40 \sim 34.60$ & 0.22 & 0.96 \\
\hline & WW & $29.07 \pm 5.74$ & $14.80 \sim 46.80$ & 0.20 & 0.97 \\
\hline \multirow[t]{2}{*}{ LSIT } & $\mathrm{DS}$ & $16.19 \pm 3.00$ & $9.20 \sim 26.20$ & 0.19 & 0.96 \\
\hline & WW & $22.9 \pm 4.23$ & $13.40 \sim 49.20$ & 0.18 & 0.96 \\
\hline \multirow[t]{2}{*}{ LIBSIT } & $\mathrm{DS}$ & $30.37 \pm 9.53$ & $8.8 \sim 57.00$ & 0.31 & 0.97 \\
\hline & WW & $41.20 \pm 13.19$ & $12.8 \sim 68.00$ & 0.32 & 0.97 \\
\hline \multirow[t]{2}{*}{ SST } & $\mathrm{DS}$ & $0.51 \pm 0.61$ & $0 \sim 3$ & 1.21 & 0.63 \\
\hline & WW & $0.38 \pm 0.45$ & $0 \sim 3$ & 1.19 & 0.44 \\
\hline
\end{tabular}




\begin{tabular}{|c|c|c|c|c|c|}
\hline \multirow[t]{2}{*}{ SSM } & DS & $0.02 \pm 0.07$ & $0 \sim 0.6$ & 3.97 & 0.21 \\
\hline & WW & $0 \pm 0$ & $0 \sim 0$ & ND & ND \\
\hline \multirow[t]{2}{*}{$\mathrm{SSB}$} & $\mathrm{DS}$ & $2.27 \pm 0.76$ & $0.20 \sim 4.80$ & 0.34 & 0.88 \\
\hline & WW & $1.23 \pm 0.69$ & $0 \sim 3.80$ & 0.56 & 0.41 \\
\hline \multirow[t]{2}{*}{ NGS } & $\mathrm{DS}$ & $34 \pm 5.85$ & $19 \sim 59$ & 0.17 & 0.85 \\
\hline & WW & $35 \pm 4.44$ & $23 \sim 49$ & 0.13 & 0.54 \\
\hline \multirow[t]{2}{*}{$\mathrm{GY}$} & $\mathrm{DS}$ & $106.37 \pm 27.66$ & $38.79 \sim 209.61$ & 0.26 & 0.31 \\
\hline & WW & $136.69 \pm 36.63$ & $54.17 \sim 272.16$ & 0.27 & 0.38 \\
\hline \multirow[t]{2}{*}{ GYP } & $\mathrm{DS}$ & $577.36 \pm 219.59$ & $67.83 \sim 1312.45$ & 0.38 & 0.78 \\
\hline & WW & $753.52 \pm 302.41$ & $40.18 \sim 1603.01$ & 0.40 & 0.81 \\
\hline \multirow[t]{2}{*}{ TGWG } & $\mathrm{DS}$ & $9.99 \pm 2.85$ & $5.96 \sim 20.57$ & 0.29 & 0.57 \\
\hline & WW & $9.04 \pm 2.76$ & $4.57 \sim 15.61$ & 0.31 & 0.46 \\
\hline \multirow[t]{2}{*}{ TGW } & $\mathrm{DS}$ & $32.10 \pm 5.73$ & $18.03 \sim 42.63$ & 0.18 & 0.81 \\
\hline & WW & $32.56 \pm 5.00$ & $20.40 \sim 45.70$ & 0.15 & 0.86 \\
\hline \multirow{2}{*}{ SWSCF } & $\mathrm{DS}$ & $204.67 \pm 34.90$ & $140.75 \sim 298.50$ & 0.17 & 0.71 \\
\hline & WW & $150.31 \pm 35.01$ & $73.65 \sim 242.65$ & 0.23 & 0.78 \\
\hline \multirow[t]{2}{*}{ SWSCG } & $\mathrm{DS}$ & $268.06 \pm 44.54$ & $140.63 \sim 346.37$ & 0.17 & 0.80 \\
\hline & WW & $196.04 \pm 42.50$ & $119.42 \sim 271.09$ & 0.22 & 0.76 \\
\hline \multirow[t]{2}{*}{ AESWSC } & $\mathrm{DS}$ & $22.05 \pm 12.09$ & $-58.30 \sim 44.24$ & 0.55 & 0.47 \\
\hline & WW & $21.21 \pm 13.35$ & $-13.35 \sim 50.47$ & 0.63 & 0.49 \\
\hline \multirow[t]{2}{*}{ GFEE } & $\mathrm{DS}$ & $31.61 \pm 8.53$ & $9.00 \sim 91.16$ & 0.27 & 0.44 \\
\hline & WW & $28.23 \pm 9.20$ & $9.94 \sim 86.27$ & 0.33 & 0.52 \\
\hline \multirow[t]{2}{*}{ GFEL } & $\mathrm{DS}$ & $0.48 \pm 11.73$ & $-52.26 \sim 28.62$ & 0.24 & 0.69 \\
\hline & WW & $4.33 \pm 11.82$ & $-51.62 \sim 27.36$ & 0.27 & 0.73 \\
\hline
\end{tabular}

\section{Copyrights}

Copyright for this article is retained by the author(s), with first publication rights granted to the journal.

This is an open-access article distributed under the terms and conditions of the Creative Commons Attribution license (http://creativecommons.org/licenses/by/4.0/). 